REVIEW

\title{
Spilled gall stones during laparoscopic cholecystectomy: a review of the literature
}

\author{
T Sathesh-Kumar, A P Saklani, R Vinayagam, R L Blackett
}

Postgrad Med J 2004;80:77-79. doi: 10.1136/pmi.2003.006023

Laparoscopic cholecystectomy is associated with spillage of gall stones in $5 \%-40 \%$ of procedures, but complications occur very rarely. There are, however, isolated case reports describing a range of complications occurring both at a distance from and near to the subhepatic area. This review looks into the various modes of presentation, ways to minimise spillage, treating the complications, and the legal implications.

See end of article for authors' affiliations

Correspondence to: Mr T Sathesh-Kumar, Department of Surgery, University Hospital of North Durham, Durham DHI 5TW, UK; sathesh87@hotmail.com

Submitted 29 January 2003 Accepted 18 August 2003 nnovation creates opportunities and technical advances that change clinical practice. With the popularity and quality of diagnostic ultrasound and the therapeutic option of laparoscopic cholecystectomy, more gall stones are now detected and consequently operated upon. With better patient satisfaction and a shorter hospital stay, laparoscopic cholecystectomy has become the method of choice. However, this change in practice from open surgery has led to different problems such as biliary tract injuries and intraoperative spillage of stones. The first complication, though serious, can be minimised with experience, supervision, and good training, whereas the latter complication of spilled gall stones is often ignored. Gall stone spillage during laparoscopic cholecystectomy is common. This problem occurs less frequently in open surgery and the spilt stones are easy to retrieve. ${ }^{1}$ Fortunately, clinically significant complications resulting from stones left in the peritoneum are extremely uncommon and because of this there

\section{INCIDENCE}

Perforation of the gall bladder occurs fairly frequently during laparoscopic cholecystectomy and is reported in the range of $10 \%-40 \%$ in various series (table 1$).^{2-7}$ The incidence of gall stone spillage is less frequent and the true incidence of unretrieved stones is difficult to determine. Some series quote a range 6\%$30 \% .^{8-10}$ Spillage of stones can occur during dissection of the gall bladder off the liver bed, tearing with grasping forceps, or during extraction of the gall bladder through one of the port sites. The incidence is more common when operating on an acutely inflamed gall bladder ${ }^{2}$; it is also more common in men, the elderly, obese patients, and in the presence of adhesions. ${ }^{5}$ Stones spilled may remain in the peritoneal cavity adjacent to the liver or may migrate to various distant sites. These stones can cause a range of complications and are discussed in this has not been much discussion of the problem. review article. In the majority of cases, these stones usually cause no bother and remain benign. Complications that result from these stones are said to occur in $0.08 \%-0.3 \%$ of patients. ${ }^{211}$

\section{PRESENTATION}

Isolated case reports in the surgical literature convey the varied modes of clinical presentations arising secondary to stone spillage (table 2).

The combination of pneumoperitoneum and peritoneal irrigation disperses calculi within the peritoneal cavity. This probably accounts for unusual sites of these complications. The exact reason why only a fraction of patients develop complications after stone spillage is uncertain. Multiple pigment stones (whose aetiology is infection) and the presence of infected bile lead to an inflammatory reaction and abscess formation. The time interval after surgery for these to present varies from as short as one month to as long as 20 years, ${ }^{133}$ with a peak incidence usually around four months. In most instances, the body's immune mechanisms cope, leading to spontaneous resolution. However, infective complications are noticed more often in elderly patients because of poorer immunological reaction. ${ }^{33}$ Often the patients presenting with an abscess can be afebrile and have a normal white cell count.

\section{PREDISPOSING FACTORS FOR COMPLICATIONS}

The fate of the intraperitoneal gall stone has provoked several exciting experimental studies. Cline et al implanted sterile gall stones in the peritoneal cavity of rats. ${ }^{34}$ The results of the study suggested spillage of sterile stones should not cause increased morbidity during or after laparoscopic cholecystectomy. Zorluoglu et al implanted gall stones inside the peritoneal cavity of the rats in combination with either sterile bile or infected bile, and they came to the conclusion that the combination of multiple stones and infected bile increased the incidence of adhesions and intraabdominal abscesses. ${ }^{35}$ Another study conducted in rats by Gurleyik et al came to the conclusion that chemical composition of the stones has a significant influence on the fate of intra-abdominal gall stones, and infection may aggravate local reactions and complications. ${ }^{36}$ Increased adhesions and abscess formation has been shown in other studies on rat. ${ }^{37}$ Infective complications are more likely to occur with bilurubinate stones because these stones often contain viable bacteria. ${ }^{39}$ 
Table 1 Complications of laparoscopic cholecystectomy reported in various series (percentages in parentheses)

\begin{tabular}{lllll}
\hline Series & Laparoscopic cholecystectomy & Bile leak & Spilled stones & Postoperative complications \\
\hline Schafer et $a^{\beta}$ & 10174 & - & $581(5.7)$ & $8(0.08)$ \\
Memon et $a^{\beta}$ & 856 & - & $106(12.3)$ & $5(0.58)$ \\
Diez et $\left.a\right|^{4}$ & 3686 & $627(17)$ & $254(6.9)$ & $12(0.32)$ \\
Rice et $\left.a\right|^{5}$ & 1059 & $306(28.9)$ & 103 & $3(0.28)$ \\
Sarli et $\left.a\right|^{\beta}$ & 1127 & - & $131(11.6)$ & - \\
Kimura et ap & 110 & $29(26.3)$ & $3(2.7)$ & - \\
\hline
\end{tabular}

\section{INVESTIGATIONS}

The diagnosis is often delayed due to the unusual site of the abscess formation coupled with the lack of awareness of stone spillage during previous cholecystectomy. Only a high index of clinical suspicion may lead to correct identification. Ultrasound, computed tomography, and magnetic resonance imaging (MRI) are valuable as diagnostic tools. Radiologists should consider spilled stones as a potential source of recurrent abscesses in any patient presenting months or years after laparoscopic cholecystectomy. The presence of calculi within the abscess can often be identified using ultrasonography, computed tomography, or MRI and is diagnostic of spilled stones complicated by abscess formation. However, a non-opaque calculus within an abscess may not be visualised by standard imaging techniques and could result in confusion with diagnosis of abscess due to other causes, such as unusual infections like actinomycosis or tumour.

Ultrasound may identify radiolucent biliary stones in the middle of the inflammatory mass by detecting the hyperechoic acoustic signals from these stones. Ultrasound is more sensitive in detecting stones in abscesses compared with $\mathrm{MRI}^{40}$ because with MRI it is difficult to differentiate between stones and gas in an abscess. Ultrasound is also more convenient and cost effective.

\section{REMOVAL OF SPILLED STONES}

Primary (prevention is better than cure)

(A) During surgery

Every attempt should be made to avoid spillage during surgery. Careful dissection and identification of correct

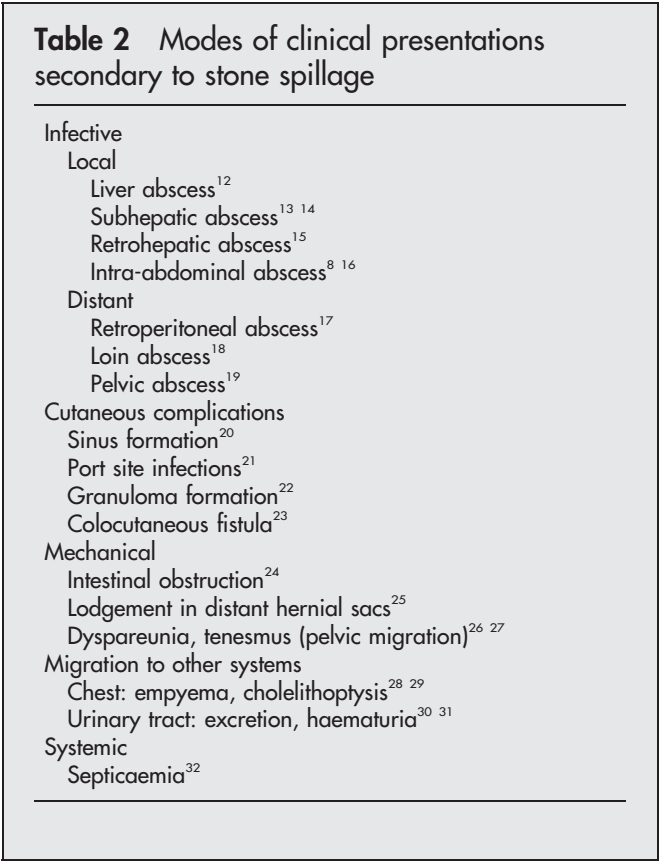

planes between the wall of the gall bladder and surrounding structures should be strictly adhered to. Aspiration of a gall bladder full of bile before dissection to ease the tension on the wall can facilitate dissection.

\section{(B) During extraction}

Use of retrieval bags to retrieve the gall bladder decreases the chances of spillage during extraction and avoids inadvertent spillage to or contamination within port site wounds.

\section{Secondary (what to do after spillage?)}

In case of spillage, efforts should be made to retrieve the lost stones and the peritoneal cavity should be irrigated with saline to dilute any infected bile. Attempts at repairing gall bladder perforations are often unsatisfactory. Use of retrieval bags or even a surgical glove with a purse string attached to the opening is recommended to collect any spilled stones and the gall bladder. ${ }^{21}$ Other techniques recommended are placement of extra ports, use of 30-45 degree telescopes, copious irrigation, and pressure ejection whereby the cannula is manoeuvred directly over these stones and the port opened rapidly to eject stones through it.

\section{To convert to open or not?}

Conversion to open surgery for removal of spilled stones recognised during laparoscopic cholecystectomy is a controversial question. Although spillage can lead to severe postoperative complications, the incidence and mortality after it are extremely low. On this basis, routine conversion to open technique to retrieve the stones is not indicated.

Tertiary (treatment of complications of spilled stones) In the literature, various methods have been described to deal with the infective complications associated with spilled stones. Treatment of complications basically depends on the location of the problem.

Abdominal wall abscess from stones caught at the port site can be dealt with by local drainage and evacuation of the stones. Stones which are the foci of infection in these abscesses and sinuses should be completely removed for a cure. ${ }^{2021}$

Intra-abdominal abscesses can be dealt with percutaneously by minimally invasive technique ${ }^{41}$ and laparotomy where this technique fails. ${ }^{43}$ The percutaneous procedure has the advantage of being less invasive, having a short hospital stay and minimal discomfort, and is ideally suited for old patients. Computed tomography guided drainage of the pus is first done with a pigtail catheter. A few weeks later the tract is dilated with a dilator system and a nephroscope is passed through it and stones are removed. ${ }^{42}$ Treatment is not complete until all the stones that are present in the abscess are removed. The size of the stone is an important determinant. Smaller stones usually less than $1 \mathrm{~cm}$ can often be removed through the nephroscope and using a basket. Larger ones need fragmentation by mechanical means or lithotripsy before attempting removal. Ultrasonic lithotripsy requires a rigid endoscope and keeps stone fragments to a 
minimum, thereby minimising the risk of breaking an infected stone into tiny fragments, which may serve as a nidus for further infection. In dealing with a deep seated abscess with a tortuous tract electrohydraulic lithotripsy in association with choledochoscopy is a good alternative. ${ }^{43} \mathrm{~A}$ completion contrast study (abscessogram) is recommended to check for the intactness of the cavity and for any retained stones.

Gall stones found at distant sites, as described in some case reports (table 2), have been an incidental finding and can be found in a hernial sac, in urine, or in sputum. Gall stones causing vesical granulomas resulting in haematuria have been dealt with by cystoscopic excision of the granulomas. ${ }^{31}$

\section{CONCLUSION}

Complications arising from spillage of gall stones during laparoscopic cholecystectomy are extremely rare. They can present months or years after the cholecystectomy with septic complications not necessarily located in the right upper quadrant.

The surgeon should take utmost care to prevent spillage of stones and attempt to remove all visible stones at the time of surgery. If spillage occurred it should be recorded clearly in the operative notes and there is no indication for routine conversion to open surgery. Patients should be informed to minimise any legal implications, and to aid in the early diagnosis of later complications.

\section{Authors' affiliations}

T Sathesh-Kumar, Department of Surgery, University Hospital of North Durham, Durham, UK

A P Saklani, Department of Surgery, North Staffordshire Hospital NHS Trust, Stoke on Trent, UK

R Vinayagam, Department of Surgery, Grantham and District Hospital NHS Trust, Grantham, Lincolnshire, UK

R L Blackett, Department of Surgery, Nevill Hall Hospital, Abergavenny, Monmouthshire, UK

\section{REFERENCES}

1 Rothlin MA, Schob O, Schlumpf R, et al. Stones spilled during cholecystectomy: a long-term liability for the patient. Surg Laparosc Endosc 1997:7:432-4.

2 Schafer M, Suter C, Klaiber C, et al. Spilled gallstones after laparoscopic cholecystectomy. A relevant problem? A retrospective analysis of 10,174 laparoscopic cholecystectomies. Surg Endosc 1998;12:291-3.

3 Memon MA, Deeik RK, Maffi TR, et al. The outcome of unretrieved gallstones in the peritoneal cavity d uring laparoscopic cholecstectomy. A prospective analysis. Surg Endosc 1999;13:848-57.

4 Diez J, Arozamena C, Gutierez L, et al. Lost stones during laparoscopic cholecstectomy. HPB Surg 1998;11:105-8; discussion 108-9.

5 Rice DC, Memon MA, Jamison RL, et al. Long term consequences of intraoperative spillage of bile and gall stones during laparoscopic cholecystectomy. J Gastrointest Surg 1997;1:85-91.

6 Sarli L, Pietra N, Costi R, et al. Gallbladder perforation during laparoscopic cholecystectomy. World J Surg 1999;23:1186-90.

7 Kimura T, Goto H, Takeuchi Y, et al. Intraabdominal contamination after gallbladder perforation during laparoscopic cholecystectomy and its complications. Surg Endosc 1996;10:888-91.

8 Catarci M, Zaraca F, Scaccia M, et al. Lost intraperitoneal stones after laparoscopic cholecystectomy: harmless sequela or reason for reoperation? Surg Laparosc Endosc 1993;3:318-12.

9 Fitzgibbons RJ, Annibali R, Litke BS. Gallbladder perforation and gallstone removal: open versus closed laparoscopy and pneumoperitoneum. Am J Surg 1993; 165:497-504.

10 Soper NJ, Dunnegan DJ. Does intraoperative gallbladder perforation influence the early outcome of laparoscopic cholecystectomy? Laparosc Endosc 1991;1:156-61

11 Horton M, Florence MG. Unusual abscess patterns following dropped gallstones during laparoscopic cholecystectomy. Am J Surg 1998;175:375-9.
12 Steerman PH, Steerman SN. Unretrieved gallstones presenting as a Streptococcus bovis liver abscess. Journal of the Society of the Laparoendoscopic Surgeons 2000;4:263-5.

13 VanBrunt PH, Lanzafane RJ. Subhepatic inflammatory mass after laparoscopic cholecystectomy. Arch Surg 1994;129:882-3.

14 Sinha AN, Shivaprasad G, Rao AS, et al. Subphrenic abscess following laparoscopic cholecystectomy and spilled gallstones. Indian J Gastroenterol 1998;17:108-9.

15 Gretschel S, Engelmann L, Estevez-Schwarz, et al. Wolf in sheep's clothing: spilled gallstones can cause severe complications after endoscopic surgery. Surg Endosc 2001;15:98-101.

16 Mellinger JD, Eldridge TJ, Eddelman ED, et al. Delayed gallstone abscess following laparoscopic cholecystectomy. Surg Endosc 1994;8:1332-4.

17 Parra-Davila E, Munshi IA, Armstrong JH, et al. Retroperitoneal abscess as a complication of retained gallstones following laparoscopic cholecystectomy. $J$ Laparoendosc Adv Surg Tech A 1998;8:89-93.

18 Gallinaro RN, Miller FB. The lost gallstone. Complication after laparoscopic cholecystectomy. Surg Endosc 1994;8:913-4.

19 Protopapas A, Milingos S, Diakomanolis E, et al. Septic lithiasis of the pelvis. Surg Endosc 2003;17:159.

20 Cacdac RG, Lakra YP. Abdominal wall sinus tract secondary to gall stones. A complication of laparoscopic cholecystectomy. J Laparoendosc Surg 1993;3:509-11.

21 Yao CC, Wong HH, Yang CC, et al. Abdominal wall abscess secondary to spilled gallstones: late complication of laparoscopic cholecystectomy and preventive measures. Laparoendosc Adv Surg Tech A 2001;11:47-51.

22 Golub R, Nwogu C, Cantu R, et al. Gall stone shrapnel contamination during laparoscopic cholecystectomy. Surg Endosc 1994;8:898-900.

23 Patterson EJ, Nagy AG. Don't cry over spilled stones? Complications of gallstones spilled during laparoscopic cholecystectomy: case report and literature review. Can J Surg 1997;40:249-50.

24 Tekin A. Mechanical small bowel obstruction secondary to spilled stones. J Laparoendosc Adv Surg Tech A 1998;8:157-9.

25 Rosin D, Korianski Y, Yudich A, et al. Lost gallstones found in a hernial sac. J Laparoendosc Surg 1995;5:409-11.

26 Chanson C, Nassiopoulos K, Petropoulos P. [Complications of intraperitoneal gallstones.] Article in French. Schweiz Med Wochenschr 1997;127:1323-8.

27 Pfeifer ME, Hansen KA, Tho SP, et al. Ovarian cholelithiasis after laparoscopic cholecystectomy associated with chronic pelvic pain. Fertil Steril 1996:66:1031-2.

28 Downie GH, Robbins MK, Souza JJ, et al. Cholelithoptysis: a complication of laparoscopic cholecystectomy. Chest 1993;103:616-17.

29 Kelty CJ, Thorpe JA. Empyema due to spilled stones during laparoscopic cholecystectomy. Eur J Cardiothorac Surg 1998;14:445-6.

30 Castro MG, Alves AS, Oliveira CA, et al. Elimination of biliary stones through the urinary tract: a complication of the laparoscopic cholecystectomy. Rev Hosp Clin Fac Med Sao Paulo 1999;54:209-12.

31 Famulari C, Pirrone G, Macri A, et al. The vesical granuloma: rare and late complication of laparoscopic cholecystectomy. Surg Laparosc Endosc Percutan Tech 2001;11:368-71.

32 Van Mierlo PJ, De Boer SY, Van Dissel JT, et al. Recurrent staphylococcal bacteraemia and subhepatic abscess associated with gallstones spilled during laparoscopic cholecystectomy two years earlier. Neth J Med 2002;60: 177-80.

33 Brueggemeyer MT, Saba AK, Thibodeaux LC. Abscess formation following spilled gallstones during laparascopic cholecystectomy. Journal of the Society of the Laparoendoscopic Surgeons 1997;1:145-52.

34 Cline RW, Poulos E, Clifford EJ. An assessment of potential complications caused by intraperitoneal gallstones. Am Surg 1994;60:303-5.

35 Zorluoglu A, Ozquc $\mathrm{H}$, Yilmazlar $\mathrm{T}$, et al. Is it necessary to retrieve dropped gallstones during laparascopic cholecystectomy? Surg Endosc 1997;1 1:64-6.

36 Gurleyik E, Gurleyik G, Yucel O, et al. Does chemical composition have an influence on the fate of intraperitoneal gallstone in rat? Surg Laparosc Endosc 1998:8:113-6

37 Johnston S, O'Malley K, McEntee G, et al. The need to retrieve the dropped stone. Am J Surg 1994;167:608-10.

38 Leland DG, Dawson DL. Adhesions and experimental intraperitoneal gallstones. Contemp Surg 1993:42:273-5.

39 Stewart L, Smith A, Pellegrini CA, et al. Pigment gallstones form as a composite of bacterial micro-colonies and pigment solids. Ann Surg 1987;206:242-50.

40 Morrin MM, Kruskal JB, Hochman MG et al. Radiological features of complications arising from dropped gall stones in laparoscopic cholecystectomy patients. AJR 2000;174:1441-5.

41 Albrecht RM, Eghtestad B, Gibel L, et al. Percutaneous removal of spilled gallstones in a subhepatic abscess. Am Surg 2002;68:193-5.

42 Zamir G, Lyass S, Pertsemlidis D, et al. The fate of dropped gallstones during cholecystectomy. Surg Endosc 1999;13:68-70.

43 Campbell WB, Mc Garity WC. An unusual complication of laparoscopic cholecystectomy. Am Surg 1992;58:641-42. 